\title{
Genetic variants associated with development of TMD and its intermediate phenotypes: the genetic architecture of TMD in the OPPERA prospective cohort study
}

\author{
Shad B. Smith ${ }^{1}$, Ellen Mir ${ }^{1,2}$, Eric Bair ${ }^{1,2}$, Gary D. Slade ${ }^{1,3,4}$, Ron Dubner ${ }^{5}$, Roger B. \\ Fillingim ${ }^{6}$, Joel D. Greenspan ${ }^{5}$, Richard Ohrbach ${ }^{7}$, Charles Knott ${ }^{8}$, Bruce Weir ${ }^{9}$, William \\ Maixner ${ }^{1,10}$, and Luda Diatchenko ${ }^{1,11}$ \\ ${ }^{1}$ Regional Center for Neurosensory Disorders, University of North Carolina at Chapel Hill, Chapel \\ Hill, NC \\ ${ }^{2}$ Department of Biostatistics, University of North Carolina at Chapel Hill, Chapel Hill, NC \\ ${ }^{3}$ Department of Dental Ecology, University of North Carolina at Chapel Hill, Chapel Hill, NC \\ ${ }^{4}$ Department of Epidemiology, University of North Carolina at Chapel Hill, Chapel Hill, NC \\ ${ }^{5}$ Department of Neural and Pain Sciences, and Brotman Facial Pain Center, University of \\ Maryland Dental School, Baltimore, MD \\ ${ }^{6}$ Department of Community Dentistry and Behavioral Science, University of Florida, Gainesville, \\ $\mathrm{FL}$ \\ ${ }^{7}$ Department of Oral Diagnostic Services, University at Buffalo, Buffalo, NY \\ ${ }^{8}$ Battelle Memorial Institute, Durham, NC \\ ${ }^{9}$ Department of Biostatistics, University of Washington, Seattle, WA \\ ${ }^{10}$ Department of Pharmacology, University of North Carolina at Chapel Hill, Chapel Hill, NC \\ ${ }^{11}$ Carolina Center for Genome Sciences at Chapel Hill, Chapel Hill, NC
}

\section{Abstract}

Genetic risk factors are believed to combine with environmental exposures and contribute to risk of developing temporomandibular disorder (TMD). In this prospective cohort study, 2,737 people without TMD were assessed for common genetic variation in 358 genes known to contribute to nociceptive pathways, inflammation, and affective distress. During a median follow-up period of 2.8 years, 260 people developed first-onset TMD. Hazard ratios (HRs) were computed as measures of association between 2,924 single nucleotide polymorphisms (SNPs) and TMD incidence. After correction for multiple testing, no single SNP was significantly associated with risk of onset TMD. However, several SNPs exceeded Bonferroni correction for multiple comparison or false discovery rate thresholds ( $\mathrm{FDR}=0.05,0.1$, or 0.2 ) for association with intermediate phenotypes shown to be predictive of TMD onset. Non-specific orofacial symptoms were associated with voltage-gated sodium channel, type 1 alpha subunit (SCN1A, rs6432860,

(C) 2013 The American Pain Society. Published by Elsevier Inc. All rights reserved.

Corresponding Author: Luda Diatchenko, CB 7450, School of Dentistry, University of North Carolina at Chapel Hill, Chapel Hill, NC 27514, phone: 919-261-7886, fax: 919-287-2924, lbdiatch@email.unc.edu, http://genomics.unc.edu/diatchenko/diatchenko.htm.

Publisher's Disclaimer: This is a PDF file of an unedited manuscript that has been accepted for publication. As a service to our customers we are providing this early version of the manuscript. The manuscript will undergo copyediting, typesetting, and review of the resulting proof before it is published in its final citable form. Please note that during the production process errors may be discovered which could affect the content, and all legal disclaimers that apply to the journal pertain. 
$\left.\mathrm{p}=2.77 \times 10^{-5}\right)$ and angiotensin-I converting enzyme $2\left(A C E 2\right.$, rs $\left.1514280, \mathrm{p}=4.86 \times 10^{-5}\right)$, global psychological symptoms with prostaglandin-endoperoxide synthase 1 (PTGS1, rs3842803, $\left.\mathrm{p}=2.79 \times 10^{-6}\right)$, stress and negative affectivity with amyloid- $\beta(\mathrm{A} 4)$ precursor protein $(A P P$, rs $466448, \mathrm{p}=4.29 \times 10^{-5}$ ), and heat pain temporal summation with multiple PDZ domain protein $\left(M P D Z, r s 10809907, \mathrm{p}=3.05 \times 10^{-5}\right)$. The use of intermediate phenotypes for complex pain diseases revealed new genetic pathways influencing risk of TMD.

\section{Keywords}

temporomandibular disorders; genetic risk factors; incidence; chronic pain; intermediate phenotypes

\section{Introduction}

Idiopathic pain disorders such as temporomandibular disorders (TMD) are heterogeneous in presentation and multifactorial in etiology, ${ }^{24}$ both of which may be due in part to genetic influences. We have previously hypothesized that persistent pain conditions result from two parallel domains of vulnerability, each comprised of a temporally-dependent mosaic of subclinical traits. ${ }^{16}$ The first domain, pain amplification, may arise due to injury/trauma, pro-inflammatory physiological state, impaired pain regulatory mechanisms, or autonomic dysregulation. The second domain, psychological distress, can manifest as somatization, anxiety, depression, stress response, or catastrophizing. Each of these domains is modulated by numerous biological processes and probably influenced by many genes.

Genetic risk factors likely play a role in the etiology of TMD, based on a twin study that attributed $44 \%$ of variation in the occurrence of TMD to genetic inheritance. ${ }^{73}$ Case-control studies of TMD have reported associations with genes in the serotonergic pathway, including serotonin transporter $S L C 6 A 4,{ }^{35,53}$ serotonin $2 \mathrm{~A}$ receptor $H T R 2 A,{ }^{49}$ and the serotonin metabolic enzyme tryptophan hydroxylase $1 \mathrm{TPH} .{ }^{21}$ Adrenergic mechanisms have also been implicated, based on findings that polymorphisms in both the $\beta 2$-adrenergic receptor $A D R B 2^{15}$ and catechol- $O$-methyltransferase $C O M T^{14}$ are associated with TMD risk. The high proportion of female TMD subjects in many studies has prompted consideration of the estrogen receptor gene ESRI as a strong candidate for association with TMD, although with conflicting results. ${ }^{37,40,42,59}$ Similarly, commonly occurring genetic variants have been associated with fibromyalgia and chronic widespread pain, including ADRB2, ${ }^{36,75}$ COMT, ${ }^{6,46,71}$ TAAR1, ${ }^{66}$ HTR2A ${ }^{47}$ and SLC6A4. ${ }^{9,51}$ Other painful conditions found to have genetic associations include headache, ${ }^{64}$ irritable bowel syndrome, ${ }^{61}$ vulvar vestibulitis, ${ }^{34}$ and low back pain, ${ }^{11,12,50,68}$.

In the first phase of the Orofacial Pain: Prospective Evaluation and Risk Assessment (OPPERA) study, we assessed 358 candidate pain genes in a case-control study of 348 chronic TMD subjects and 1,612 TMD-free controls. ${ }^{65}$ No SNPs were statistically significantly associated with chronic TMD after correction for multiple testing, but findings supported a contribution from candidate genes including HTR2A, COMT, glucocorticoid receptor (NR3C1), calcium/calmodulin-dependent protein kinase type IV (CAMK4), muscarinic cholinergic receptor (CHRM2), interferon-related developmental regulator 1 (IFRD1), and the G protein-coupled receptor kinase 5 (GRK5).

An alternative strategy for discovering genetic contributions to TMD is to investigate genetic influences on intermediate phenotypes that contribute to TMD. The contribution of genetic influences relative to environmental factors may be stronger for intermediate phenotypes. Four criteria have been proposed for this approach ${ }^{27}$ where the intermediate 
phenotype: (1) is associated with TMD in the population; (2) is heritable; (3) manifests in an individual independent of active disease; and (4) co-segregates with TMD in families. Other papers in this volume address the first criterion by identifying phenotypes that predicted risk of developing first-onset TMD. The prospective cohort fulfills the third criterion because each phenotype was assessed at enrollment, prior to development of TMD.

Here we present findings from the OPPERA prospective cohort study, in which people without TMD at enrollment were followed for up to five years. One aim was to identify genetic polymorphisms that predicted incidence of first-onset TMD. Twenty-three genes belonging to major neurotransmitter systems were chosen as primary candidates; the remaining set of 335 genes was considered a discovery panel. A second aim was to identify SNPs that were associated with intermediate phenotypes that predicted TMD incidence.

\section{Materials and Methods}

\section{Study setting and participants}

The details of recruitment and characterization of the OPPERA prospective cohort have been described fully elsewhere, ${ }^{4}$ and are summarized here. A total of 3,263 initially painfree subjects were recruited by advertisements, emails, flyers and word-of-mouth between May, 2006 and November, 2008. They were recruited from communities in and around academic health centers at four US study sites: Baltimore MD, Buffalo NY, Chapel Hill NC, and Gainesville FL. These subjects included both males and females of diverse racial and ethnic backgrounds, and were aged 18-44 years at enrollment. Only subjects $(n=2,737)$ who returned at least one follow-up screening questionnaire were included in the prospective study of first-onset TMD. For this subset of OPPERA subjects, the mean age at enrollment was 27.1 years (standard deviation $=7.8$ years); 1,630 were female and 1,107 were male (female:male ratio $=1.5: 1)$. Approximately half $(n=1,612)$ of this prospective cohort sample was used previously in the OPPERA baseline case-control study of chronic TMD. ${ }^{65}$ These subjects, enrolled without TMD at baseline, were considered controls who were contrasted with 185 subjects who had examiner-verified chronic TMD (i.e., "cases"). None of the chronic TMD cases from that study were used in any analysis described in the present prospective study of first-onset TMD.

\section{Ethical conduct of research with humans}

The OPPERA study was reviewed and approved by institutional review boards at each of the four study sites and at the data coordinating center, Battelle Memorial Institute. Participants verbally agreed to a screening interview done by telephone and provided informed, signed consent for all other study procedures, including blood draw and genetic analysis.

\section{Genotyping}

This paper focuses on genetic variants assessed at baseline that have been described in detail elsewhere ${ }^{65}$ and summarized here.

At enrollment, whole blood was collected by venipuncture from study participants who provided consent for genotyping. Blood was collected into 5mL EDTA containing polyethylene vacutainers, which were stored at $-80^{\circ} \mathrm{C}$. Genomic DNA was purified utilizing protocols based on Qiagen ${ }^{\mathrm{TM}}$ Extraction Kits at Cogenics, Inc. (now Integrated Laboratory Systems, Morrisville, NC).

Samples were genotyped using the Algynomics (Chapel Hill, NC) Pain Research Panel, ${ }^{66}$ a dedicated chip-based platform utilizing the Affymetrix MegAllele technology. The panel 
assesses 3295 single nucleotide polymorphisms (SNPs) representing 358 genes known to be involved in systems relevant to pain perception (complete list provided through http:// www.algynomics.com/pain-research-panel.html). The panel includes genes putatively involved in intermediate processes underlying TMD, such as nociceptive transmission, inflammation, and mood and affect. The SNPs selected for the panel prioritize functional variants such as those that code for non-synonymous changes or result in differences in expression or alternative splicing, while others were selected as representative markers of regions with high linkage disequilibrium (LD), containing many correlated SNPs that are inherited in blocks, in order to "tag" untyped variation.

Twenty-three genes (Supplemental Table 1) were chosen a priori as "first tier" candidate genes, and, as described previously, ${ }^{65}$ the probability of type I error was adjusted to account for tests of their 211 SNPs in the analysis reported below. Quality assessment of Pain Research Panel genotypes was performed using PLINK v.1.07 (Broad Institute, Cambridge MA) ${ }^{57}$ as previously described. ${ }^{65}$ An identity-by-state analysis was performed using principal components analysis (PCA) on the genotypes to cluster individuals according to racial heritage. The first two principal components (eigenvectors) were retained for use as covariates representing racial background in the association testing, in order to adjust for population stratification. ${ }^{56}$ Genotyping results were returned for 3221 unique samples, which included enrollees in the prospective cohort study as well as cases for the case-control study. The overall genotyping call rate was $99.1 \%$ and repeated sample concordance was $99.8 \%$.

\section{Phenotypic assessment}

At three-monthly intervals after enrollment, study participants were asked to complete a screening questionnaire that asked about TMD pain symptoms. ${ }^{4}$ Those reporting symptoms were invited to study clinics for a follow-up examination that determined presence or absence painful TMD using OPPERA's implementation of the research diagnostic criteria for TMD. ${ }^{18}$ Specifically, the 260 incident cases satisfied two criteria for TMD: (1) symptoms of orofacial pain reported for $\geq 5$ days/month; and (2) examiner findings of TMD myalgia, arthralgia, or both. For descriptive purposes, the rate of first-onset TMD was calculated as the number of people with first-onset TMD divided by sum of follow-up intervals.

A large number of potential risk factors for onset TMD were evaluated in OPPERA, including measures related to clinical symptoms, psychosocial profile, somatic sensitivity, and autonomic response. Given the large number of raw and derived variables assessed in OPPERA subjects at enrollment, we narrowed our selection of phenotypes for genetic analysis to reduce the burden of multiple testing. For measures of psychological status and experimental pain sensitivity, we used PCA to recalculate factor scores first described in our baseline case-control study. ${ }^{23,28}$ This reduced the large number of raw variables measured in each domain, thereby mitigating the number of tests requiring Bonferroni adjustment and producing more stable measures of the underlying construct compared to individual measures. The PCA findings for this prospective cohort study are described elsewhere in this supplement. ${ }^{25,29}$. Furthermore, we designated as intermediate phenotypes only those measures associated with first-onset TMD in our initially TMD-free subjects, following the definition of Gottesman et al. ${ }^{27}$ Using these criteria, we selected eight characteristics as intermediate phenotypes for this analysis, listed here with their respective univariate effect on the incidence rate of TMD (hazard ratio, or HR, adjusted for site and demographic variables). Dependent variables for the intermediate phenotypes taken from the clinical measures ${ }^{52,62}$ were: (1) the number of comorbid health conditions $(0,1$ or $\geq 2, \mathrm{HR}=1.39$ for 1 and $\mathrm{HR}=2.87$ for $\geq 2$ comorbid health conditions); (2) the number of non-specific 
orofacial symptoms $(0,1-2$ or $\geq 3, \mathrm{HR}=1.98$ for $1-2$ symptoms and $\mathrm{HR}=2.89$ for $\geq 3$ symptoms), (3) global score of the Pittsburg Sleep Quality Index (PSQI, a continuous variable, $\mathrm{HR}=1.4$ ). Tenderness at 10 separate masticatory muscle groups (temporalis, masseter, posterior mandibular and submandibular, lateral pterygoid area, and temporomandibular joint, both right and left sides) during examination procedures was also associated with first-onset TMD. For the intermediate phenotype analysis, we created a single summary variable by counting (4) the number of tender masticatory muscles for each individual, which was itself a strong predictor of TMD incidence (continuous variable, HR = 1.33). Intermediate phenotypes derived from the battery of psychosocial measures ${ }^{25}$ included: (5) the principal component from factor analysis of psychosocial measures that signified global psychological symptoms (continuous variable, HR =1.37); and (6) the principal component from factor analysis of psychosocial measures signifying stress and negative affectivity (continuous variable, $\mathrm{HR}=1.17$ ); Intermediate phenotypes associated with incident TMD from among the QST variables ${ }^{29}$ were: (7) the principal component from factor analysis of QST measures signifying pressure pain thresholds (a continuous measure, $\mathrm{HR}=1.14$ ); and (8) the principal component from factor analysis of QST measures signifying heat pain temporal summation (but only in the lowest tertile of first-pulse responders, see the accompanying paper $^{29}$ for details; continuous variable, $\mathrm{HR}=1.54$ ).

\section{Association with TMD incidence and intermediate phenotypes}

To test hypotheses about associations between genetic variants and TMD incidence rate in the 2,737 subjects with follow-up data, univariate hazard ratios were computed using Cox proportional hazard regression as implemented in the R package GenABEL v. 1.5-1. ${ }^{3}$ Hazard ratios with $95 \%$ confidence intervals $(95 \% \mathrm{CI}$ ), assuming codominant effects of genotype, were computed with adjustment for study site and the first two racial eigenvectors. Alternate genetic models, including tests of dominant and recessive inheritance, were also tested. To evaluate stratum-specific genetic effects, additional tests were performed as above in males and females separately; and in Caucasians and AfricanAmericans separately (without adjustment by racial eigenvectors). For the intermediate phenotypes, all subjects enrolled without TMD at baseline were included in analyses $(\mathrm{n}=3,037$ with phenotype and genotype data). Association tests assuming codominant effects were performed by fitting a generalized linear model in $\mathrm{R}$, in which the quantitative or binary observed phenotype was the dependent variable. Effect size and direction were estimated using beta coefficients for quantitative traits, and odds ratios (OR) for binary traits, and stratum-specific tests were performed as above.

Because we tested a large number of SNPs and several intermediate phenotypes, it was necessary to adjust our standard of statistical significance in order to maintain a desired experiment-wide $a=0.05$. It is also important to weigh the risk of false positives against the risk of false negative results (Type II errors), which are common in association studies that use conservative adjustments (such as a Bonferroni correction) evaluating large numbers of correlated markers with small effect sizes. We used the false discovery rate (FDR) method ${ }^{8}$ to control the expected proportion of false positives among associations reported as significant, adopting a threshold FDR of 0.2 . This method balances the considerations of retaining power to detect true associations after correction for multiple testing, while acknowledging that some results considered significant will be false positives.

\section{Results TMD Incidence}

The cohort of 2,737 initially TMD-free people was followed for a total of 7,404 personyears (median $=2.8$ years per person), during which time 260 people developed first-onset 
TMD, yielding an annual incidence rate of $3.5 \%$ of people per annum. Additional details regarding the demographics of subjects followed in the prospective cohort and those with acute TMD are provided in the methods article in the present supplement. ${ }^{4}$

The quantile-quantile (Q-Q) plot (Fig. 1) of the distribution of observed-log(p-values) from tests of association with TMD incidence did not differ markedly from the null distribution (genomic control $\lambda<1$ ), suggesting that adjusting for covariates was adequate to minimize the effects of population stratification and other potential sources of systematic bias. ${ }^{56}$

The results of the top 20 SNPs in the full set of SNPs are provided in Table 1. As indicated by the Q-Q plot, no statistically significant associations were observed. There were also no SNPs with a Bonferroni-corrected statistically significant association for TMD incidence among Tier 1 genes (see Supplemental Table 2 for top SNPs, and Supplemental Fig. 1 for Q-Q plot).

\section{Intermediate Phenotype Association Results}

We next assessed association between the SNP panel and intermediate phenotypes predictive of TMD incidence. As described elsewhere in this Supplement, ${ }^{25,29,52,62} \mathrm{a}$ number of measures relevant to domains of hypersensitivity and psychological distress were evaluated prospectively for association with first-onset TMD, and those that were predictive of TMD incidence were identified as intermediate phenotypes. These included four clinical variables ${ }^{52,62}$ (the number of comorbid health conditions, the number of non-specific orofacial symptoms, the number of masticatory muscle groups painful during examination procedures, and the global score of the PSQI); two factors derived from the PCA of psychosocial measures ${ }^{25}$ (global psychological symptoms and stress and negative affectivity); and two factors from the PCA of QST variables ${ }^{29}$ (pressure pain threshold and heat pain temporal summation).

Results for tests of association between each SNP and each intermediate phenotype are depicted in Q-Q plots (Fig. 2; Supplemental Fig. 2 shows additional plots for tests with no results with FDR $<0.2$ and tested non-intermediate phenotypes; Supplemental Fig. 3 shows Manhattan plots for all tested phenotypes). The results for Q-Q plots are presented with $\mathrm{FDR}=0.05,0.1$, and 0.2 thresholds assessing deviation from the null distribution. Effect size estimates (relative to the minor allele) and p-values for all results that exceeded the $\mathrm{FDR}=0.02$ threshold are provided in Table 2, for the full cohort and by strata.

Association tests were performed for four clinical intermediate phenotypes: ${ }^{52,62}$ the number of (1) comorbid health conditions, (2) non-specific orofacial symptoms, (3) and masticatory muscle groups painful during examination procedures, and (4) the global score of the PSQI. The strongest association was with non-specific orofacial symptoms, including jaw stiffness, cramping, fatigue, pressure, soreness, and ache. ${ }^{52}$ Three linked SNPs within the voltagegated sodium channel, type I, alpha subunit gene SCN1A approached the corrected significance threshold for association, including a non-synonymous Ala-> Thr polymorphism (best SNP rs6432860, minor allele (MA) $=\mathrm{A}, \mathrm{p}=2.77 \times 10^{-5}, \mathrm{OR}=1.42,95 \%$ CI $1.21-$ 1.68). Another strong association was observed at an intronic SNP in the angiotensin-I converting enzyme 2 gene, ACE2 ( $r 1514280, \mathrm{MA}=\mathrm{T}, \mathrm{p}=4.86 \times 10^{-5}, \mathrm{OR}=1.32,95 \% \mathrm{CI}$ 1.15-1.51). No associations were observed beyond the FDR $=0.2$ threshold for the other clinical measures.

Two psychological factors associated with incident TMD were tested for genetic association: global psychological symptoms, which includes characteristics such as somatization, anxiety, depression, hostility, and psychoticism; and stress and negative affectivity, which represents measures of state and trait anxiety, perceived stress, and 
neuroticism. ${ }^{25}$ The strongest association with global psychological symptoms, exceeding Bonferroni-corrected significance, was a synonymous Pro-Pro SNP in the prostaglandinendoperoxide synthase 1 gene $P T G S 1$ (rs3842803, MA $=\mathrm{C}, \mathrm{p}=2.79 \times 10^{-6}$, beta $=-0.22$, $95 \%$ CI $-0.31--0.13$ ). This SNP is rare in Caucasians (MAF $<0.01$ ), but fairly common in African-Americans (MAF $=0.24)$; the SNP remains strongly associated in AfricanAmericans alone $\left(\mathrm{p}=3.45 \times 10^{-4}\right)$. One polymorphism was associated with the stress and negative affectivity factor, a promoter region SNP near the amyloid precursor protein gene, $A P P\left(\mathrm{rs} 466448, \mathrm{MA}=\mathrm{A}, \mathrm{p}=4.29 \times 10^{-5}\right.$, beta $=0.11,95 \%$ CI $\left.0.06-0.17\right)$.

The QST variables were summarized by five principal components, of which only two were examined as intermediate phenotypes. ${ }^{29}$ One SNP was associated with heat pain temporal summation in the lowest tertile of first-pulse responders, ${ }^{29}$ located in an intron of the multiple PDZ domain protein MPDZ ( $\mathrm{rs} 10809907, \mathrm{MA}=\mathrm{C}, \mathrm{p}=3.05 \times 10^{-5}$, beta $=0.16$, $95 \%$ CI $0.09-0.24)$. No SNPs were significantly associated with the pressure pain threshold principal component.

\section{Discussion}

In this prospective study, we did not observe significant variation in TMD incidence according to genetic polymorphisms from the panel of candidate genes. Although the cohort was large, the relatively small number of people who developed TMD limited our power to detect genetic effects of small size. Despite nominating a small "first-tier" panel of putative genes, and statistical methods that guarded against type II error, the lack of observed associations may have occurred for several reasons. While a genetic basis for chronic TMD has been established, acute onset TMD may be determined in large part by environmental factors, such as trauma, infection, or stress, and only a subset of acute TMD cases will become chronic. ${ }^{19}$ Likewise, the causes of first-onset TMD may be more heterogeneous than for chronic TMD. If so, genetic variants may be more readily discovered by clustering cases of first-onset TMD into groups with similar pathophysiology, and therefore hypothetically similar genetic determinants. Replication of suggestively associated SNPs in a second independent cohort, which this study lacks, would be necessary to provide additional evidence of genetic determination of onset TMD. To further explore the role of common genomic variation in TMD, the OPPERA group has continued enrollment of healthy and TMD subjects in preparation for a well-powered GWAS.

In contrast to the lack of results for onset TMD, we observed evidence for genetic association in a number of pronociceptive intermediate phenotypes. The objective was to find SNPs associated with intermediate phenotypes in our population limited to initially TMD-free individuals, in order to find genetic loci that increase the risk of first-onset TMD. We therefore did not use random sampling of the overall population, which narrows the generalizability of these findings to people without TMD. The SNPs associated with intermediate phenotypes possibly contribute to TMD incidence by increasing the risk of developing these intermediate phenotypes. The implicated genes were derived from a pool of pain candidate genes, each with a known physiological mechanism supporting its relevance to development of TMD. However, there is still much yet to be understood regarding the etiological pathway from genetic risk marker to pronociceptive domain through to TMD onset.

Two genes, SCNIA and ACE2, were associated with the clinical measure of non-painful orofacial symptoms, one of the predictors of TMD incidence. SCNIA encodes the alpha subunit of the voltage-gated sodium channel $\mathrm{Na}_{\mathrm{v}} 1.1$, which is involved in the generation and propagation of action potentials in sensory nerves. Mutations in SCNIA have been reported to cause several types of epilepsy, especially those associated with febrile seizures, ${ }^{74}$ and 
the gene has also been associated with short-term memory performance in a GWAS. 54 SCNIA rare mutations have been implicated in hereditary migraine, ${ }^{17}$ although the degree to which common variation in the gene affects normal sensation is unknown. Notably, this gene belongs to the same family as $S C N 9 A$, which encodes the $\mathrm{Na}_{\mathrm{v}} 1.7$ channel and which has been implicated in Mendelian disorders of spontaneous pain and insensitivity as well as altered pain thresholds and risk of chronic pain disease. ${ }^{58}$ Tight linkage disequilibrium across the SCN1A locus resulted in several panel SNPs displaying evidence of association in our study. The strongest associated SNP was rs6432860, a synonymous Val752Val substitution in exon 13; another associated SNP (rs2298771) is a non-synonymous amino acid substitution in exon 16 (rs2298771, Thr1056Ala) of unknown functional significance. Determining the true effect variant responsible for differential perception of non-painful orofacial symptoms is challenging, as numerous polymorphisms in tight LD within SCNIA result in alterations in function or expression of the Nav1.1 channel. ${ }^{54}$

The second gene associated with non-painful orofacial symptoms was ACE2, which codes for the angiotensin I-converting enzyme 2. In accordance with the function of the reninangiotensin system in regulating blood pressure and fluid balance, numerous studies have attributed genetic differences in risk of hypertension to variation in $A C E 2,{ }^{44}$ although no studies have reported association with any pain or sensory symptoms. Angiotensin related peptides have been posited as neurotransmitters in the periaqueductal gray 55 and other pain relevant brain areas, where they modulate pro-and anti-nociceptive pathways. ${ }^{10,45} \mathrm{In}$ addition to angiotensin-I, endogenous peptide substrates of ACE include bradykinin, substance $\mathrm{P}$, and opioids such as dynorphin and enkephalin, ${ }^{20,72}$ suggesting the angiotensin system plays a pivotal role underlying the relationship between blood pressure and pain sensitivity. Pharmacological inhibition of ACE has been associated with increase in nociceptive thresholds and tolerance ${ }^{30}$ and risk of complex regional pain syndrome (CRPS), ${ }^{13}$ suggesting lower levels of ACE activity due to genetic variation might underlie altered somatic sensitivity. The ACE2 locus is located on the $\mathrm{X}$ chromosome, and the effect of this SNP was stronger in males $(\mathrm{OR}=1.35)$ than females $(\mathrm{OR}=1.27)$. The SNP observed in this study is located in an intron between exons 14 and 15 , and is therefore likely to be a tag of a nearby ungenotyped polymorphism of unknown function.

A SNP in the PTGS1 gene was associated with the psychosocial factor representing global psychological symptoms, a significant and strong predictor of TMD incidence $(\mathrm{HR}=1.35)$, and a discriminant of chronic TMD cases from controls. This gene encodes prostaglandinendoperoxide synthase 1, also known as COX-1, which catalyzes the production of prostaglandins and is therefore pivotal in the regulation of neuronal sensitivity to pain and the mediation of the inflammatory response. Polymorphisms in this gene result in resistance to aspirin, ${ }^{32}$ a COX inhibitor, and have been associated with risk of colorectal cancer ${ }^{70}$ and functional dyspepsia; ${ }^{1}$ no genetic differences in pain sensitivity or risk of painful disease have been reported. Prostaglandins are involved in an array of physiological processes, suggesting that genetic factors that influence baseline or stimulated levels of prostaglandins could alter somatic sensitivity and awareness of autonomic activity, nociception, vascular muscle constriction or dilation, and gastrointestinal function. The SNP associated with global psychological symptoms, rs 3842803 , is located in the terminal exon 11 of the gene, where it results in a Pro503Pro synonymous change. The effect of this SNP was a decrease in the global psychological symptoms in African-Americans carrying the minor allele, indicating that the genetic effect is likely to inhibit prostaglandin production by attenuating the activity of COX-1.

A second association with a psychosocial factor was observed between the stress and negative affectivity factor and a SNP of the $A P P$ gene. Expressed by neurons, the amyloid- $\beta$ precursor protein is involved in synapse formation and neuronal plasticity; although its 
function is not yet fully understood, the expression of APP has been proposed as a neuroprotective response to stress. ${ }^{63}$ Proteolysis of APP results in $\beta$-amyloid, a major component of plaques in the brain that have been associated with the development of Alzheimer's disease (AD). Risk of AD, especially familial or early-onset AD, has been associated with polymorphisms of $A P P .{ }^{2,31}$ Cognitive ability and cognitive aging may also be genetically modulated by the gene ${ }^{33}$, suggesting $A P P$ polymorphism may underlie deficits in the capacity to handle stressful life events in affected individuals. The associated SNP, rs466448 (-1023T/C), is found in the promoter region of the gene, and has been shown to increase expression levels of the protein. ${ }^{41}$ The effect allele was associated with increased stress factor scores in the OPPERA cohort, suggesting a genetic link between higher levels of APP and higher perception of stress. ${ }^{60,63,69}$

A single gene, MPDZ, was associated with a QST phenotype predictive of TMD onset, heat pain temporal summation. This gene encodes a multiple PDZ domain protein, also known as MUPP1, that functions as a scaffolding protein for several $\mathrm{G}$ protein-coupled receptors involved in nociception and analgesia, including serotonergic ${ }^{7}$ and GABAergic ${ }^{5}$ receptors. Polymorphisms in MPDZ have been associated with alcoholism, both in mice ${ }^{22}$ and in humans. ${ }^{38}$ It has been suggested that $M P D Z$ variation acts on alcohol dependence via the NMDA-dependent AMPA trafficking cascade, ${ }^{39}$ which as a regulator of glutamate-related excitatory neurotransmission would be highly relevant to the phenotype of temporal summation of thermal pain as well. The SNP associated with heat pain temporal summation was located in an intron near exon 28 of the gene, and does not have any known functional significance.

Though this study provides evidence for several genes contributing to the etiology of TMD, it has a number of limitations that impact the interpretation of the findings. The power to detect clinically meaningful hazard ratios for TMD was low. Power was generally high for quantitative traits, but was still dependent on variables such as allele frequency and the underlying effect size of the SNPs. The proportion of trait variance due to genetic factors is poorly understood for TMD and the intermediate phenotypes, especially in a heterogeneous sample such as OPPERA with many environmental sources of variance. The use of derived variables such as factor scores, though intended to mitigate the problem of multiple testing, makes it difficult to interpret differences in outcome measures due to genetic factors. It is also possible that our selection of candidate genes based on known relevance to pain pathways did not include the primary genes that contribute to risk of first-onset TMD. Precedence for this comes from the large proportion of replicable associations discovered by genome-wide association studies (GWAS) that are not found in or near loci of known function or relevance to disease. ${ }^{26}$ Another caveat to the interpretation of this study is that we cannot generalize genetic association results for intermediate phenotypes to the general population, as the study design did not include subjects with orofacial pain and was not a true cross-section of the population. Finally, a statistical association between a gene and a trait of interest does not fully explain the biological basis for that relationship; further studies are required to characterize the functional consequences of these genetic polymorphisms that result in alterations in nociceptive and psychological traits.

These genes demonstrating association should be examined in other cohorts, as the power in this study alone was limited and meta-analytic methods have succeeded in confirming numerous true genetic associations with effect sizes too small to detect in single lowpowered studies. ${ }^{43,48,67,76}$ These genetic variants will be considered candidates to test association in cohorts of acute and chronic TMD of more substantial statistical power which are currently being collected. Furthermore, despite the large number of genes and variants tested, we are unable to cover the full extent of genetic variability that may influence TMD risk, such as rare variants, or genes not currently known to be relevant to pain. Instead, we 
have endeavored to test genes already implicated in pain processing, using a candidate gene analysis. While this minimized the amount of multiple testing needed to assess the observed risk factors, it will be important to extend these findings in other studies using GWAS and other high-dimension methods. This study has shown the utility of considering intermediate phenotypes, which are likely to be more strongly genetically determined and can be measured in the full cohort to improve power. By dissecting the genetic architecture underlying the physiological and behavioral domains of pain susceptibility, novel etiological pathways and therapeutic approaches may be revealed.

\section{Supplementary Material}

Refer to Web version on PubMed Central for supplementary material.

\section{Acknowledgments}

The authors would like to thank the OPPERA research staff for their invaluable contributions to this work. In addition, we express our gratitude to the participants who have devoted time and effort in support of this research.

\section{Disclosures}

This work was supported by NIH grants U01DE017018, DE016558, P01NS045685, R01DE016155, and K12DE022793, and by the Intramural Research Program of the NIH, National Institute of Environmental Health Sciences (DZ). The OPPERA program also acknowledges resources specifically provided for this project by the respective host universities: University at Buffalo, University of Florida, University of Maryland-Baltimore, and University of North Carolina-Chapel Hill. Shad Smith, Roger Fillingim and Gary Slade are consultants and equity stock holders, and William Maixner and Luda Diatchenko are cofounders and equity stock holders in Algynomics, Inc., a company providing research services in personalized pain medication and diagnostics.

\section{References}

1. Arisawa T, Tahara T, Shibata T, Nagasaka M, Nakamura M, Kamiya Y, Fujita H, Nakamura M, Yoshioka D, Arima Y, Okubo M, Hirata I, Nakano H. Association between genetic polymorphisms in the cyclooxygenase-1 gene promoter and peptic ulcers in Japan. Int J Mol Med. 2007; 20:373378. [PubMed: 17671743]

2. Athan E, Lee J, Arriaga A, Mayeux R, Tycko B. Polymorphisms in the promoter of the human APP gene Functional evaluation and allele frequencies in Alzheimer disease. Arch Neurol. 2002; 59:1793-1799. [PubMed: 12433268]

3. Aulchenko YS, Ripke S, Isaacs A, van Duijn CM. GenABEL: an R library for genome-wide association analysis. Bioinformatics. 2007; 23:1294-1296. [PubMed: 17384015]

4. Bair E, Slade GD. Study design, methods, sample characteristics and loss-to-follow-up: the OPPERA prospective cohort study. J Pain in press. (in this volume).

5. Balasubramanian S, Fam SR, Hall RA. GABA B receptor association with the PDZ scaffold Mupp1 alters receptor stability and function. J Biol Chem. 2007; 282:4162-4171. [PubMed: 17145756]

6. Barbosa F, Matsuda J, Mazucato M, de Castro Franca S, Zingaretti S, da Silva L, Martinez-Rossi N, Junior M, Marins M, Fachin A. Influence of catechol-O-methyltransferase (COMT) gene polymorphisms in pain sensibility of Brazilian fibromialgia patients. Rheumatol Int. 2012; 32:427430. [PubMed: 21120493]

7. Bécamel C, Figge A, Poliak S, Dumuis A, Peles E, Bockaert J, Lübbert H, Ullmer C. Interaction of serotonin 5-hydroxytryptamine type $2 \mathrm{C}$ receptors with PDZ10 of the multi-PDZ domain protein MUPP1. J Biol Chem. 2001; 276:12974-12982. [PubMed: 11150294]

8. Benjamini Y, Hochberg Y. Controlling the false discovery rate: a practical and powerful approach to multiple testing. J R Stat Soc B. 1995; 57:289-300.

9. Cohen H, Buskila D, Neumann L, Ebstein RP. Confirmation of an association between fibromyalgia and serotonin transporter promoter region (5- HTTLPR) polymorphism, and relationship to anxietyrelated personality traits. Arthritis Rheum. 2002; 46:845-847. [PubMed: 11920428] 
10. Costa ACO, Becker LK, Moraes ER, Romero TRL, Guzzo L, Santos RAS, Duarte IDG. Angiotensin-(1-7) induces peripheral antinociception through Mas receptor activation in an opioid-independent pathway. Pharmacology. 2012; 89:137-144. [PubMed: 22414617]

11. Costigan M, Belfer I, Griffin RS, Dai F, Barrett LB, Coppola G, Wu T, Kiselycznyk C, Poddar M, Lu Y, Diatchenko L, Smith S, Cobos EJ, Zaykin D, Allchorne A, Shen PH, Nikolajsen L, Karppinen J, Mannikko M, Kelempisioti A, Goldman D, Maixner W, Geschwind DH, Max MB, Seltzer Ze, Woolf CJ. Multiple chronic pain states are associated with a common amino acidchanging allele in KCNS1. Brain. 2010; 133:2519-2527. [PubMed: 20724292]

12. Dai F, Belfer I, Schwartz CE, Banco R, Martha JF, Tighioughart H, Tromanhauser SG, Jenis LG, Kim DH. Association of catechol-O-methyltransferase genetic variants with outcome in patients undergoing surgical treatment for lumbar degenerative disc disease. Spine J. 2010; 10:949-957. [PubMed: 20863768]

13. de Mos M, Huygen FJPM, Stricker BHC, Dieleman JP, Sturkenboom MCJM. The association between ACE inhibitors, the complex regional pain syndrome Suggestions for a neuroinflammatory pathogenesis of CRPS. Pain. 2009; 142:218-224. [PubMed: 19195784]

14. Diatchenko L, Slade GD, Nackley AG, Bhalang K, Sigurdsson A, Belfer I, Goldman D, Xu K, Shabalina SA, Shagin D, Max MB, Makarov SS, Maixner W. Genetic basis for individual variations in pain perception and the development of a chronic pain condition. Hum Mol Genet. 2005; 14:135-143. [PubMed: 15537663]

15. Diatchenko L, Anderson A, Slade G, Fillingim R, Shabalina S, Higgins T, Sama S, Belfer I, Goldman D, Max M, Weir B, Maixner W. Three major haplotypes of the B2 adrenergic receptor define psychological profile, blood pressure, and the risk for development of a common musculoskeletal pain disorder. Am J Med Genet Part B. 2006; 141B:449-462. [PubMed: 16741943]

16. Diatchenko L, Nackley A, Slade G, Fillingim R, Maixner W. Idiopathic pain disorders--pathways of vulnerability. Pain. 2006; 123:226-230. [PubMed: 16777329]

17. Dichgans M, Freilinger T, Eckstein G, Babini E, Lorenz-Depiereux B, Biskup S, Ferrari MD, Herzog J, van den Maagdenberg AM, Pusch M, Strom TM. Mutation in the neuronal voltage-gated sodium channel SCN1A in familial hemiplegic migraine. The Lancet. 2005; 366:371-377.

18. Dworkin S, LeResche L. Research diagnostic criteria for temporomandibular disorders: review, criteria, examinations and specifications, critique. J Craniomandib Disord. 1992; 6:301-55. [PubMed: 1298767]

19. Dworkin SF, Huggins KH, Le Resche L, Von Korff M, Howard J, Truelove E, Sommers E. Epidemiology of signs symptoms in temporomandibular disorders: clinical signs in cases and controls. J Am Dent Assoc. 1990; 120:273-281. [PubMed: 2312947]

20. Erdös EG. Angiotensin I converting enzyme and the changes in our concepts through the years. Lewis K. Dahl memorial lecture. Hypertension. 1990; 16:363-370. [PubMed: 2170273]

21. Etoz OA, Ataoglu H, Erdal ME. Association between tryptophan hydroxylase gene polymorphism and painful non-osseous temporomandibular disorders. Saudi Med J. 2008; 29:1352-1354. [PubMed: 18813430]

22. Fehr C, Shirley RL, Belknap JK, Crabbe JC, Buck KJ. Congenic mapping of alcohol and pentobarbital withdrawal liability loci to a <1 centimorgan interval of murine chromosome 4: identification of $M p d z$ as a candidate gene. J Neuroscience. 2002; 22:3730-3738.

23. Fillingim RB, Ohrbach R, Greenspan JD, Knott C, Dubner R, Bair E, Baraian C, Slade GD, Maixner W. Potential psychosocial risk factors for chronic TMD: descriptive data and empirically identified domains from the OPPERA Case-Control Study. J Pain. 2011; 12:T46-T60. [PubMed: 22074752]

24. Fillingim RB, Slade GD, Diatchenko L, Dubner R, Greenspan JD, Knott C, Ohrbach R, Maixner W. Summary of findings from the OPPERA Baseline Case-Control Study: Implications and future directions. J Pain. 2011; 12:T102-T107. [PubMed: 22074748]

25. Fillingim RB, Ohrbach R, Greenspan JD, Knott C, Diatchenko L, Dubner R, Bair E, Baraian C, Mack N, Slade GD, Maixner W. Psychosocial Factors Associated with Development of TMD: the OPPERA Prospective Study. J Pain in press. (in this volume). 
26. Frazer KA, Murray SS, Schork NJ, Topol EJ. Human genetic variation and its contribution to complex traits. Nat Rev Genet. 2009; 10:241-251. [PubMed: 19293820]

27. Gottesman II, Gould TD. The endophenotypic concept in psychiatry: etymology and strategic intentions. Am J Psychiatry. 2003; 160:636-645. [PubMed: 12668349]

28. Greenspan JD, Slade GD, Bair E, Dubner R, Fillingim RB, Ohrbach R, Knott C, Mulkey F, Rothwell R, Maixner W. Pain sensitivity risk factors for chronic TMD: descriptive data and empirically identified domains from the OPPERA Case Control Study. J Pain. 2011; 12:T61-T74. [PubMed: 22074753]

29. Greenspan JD, Slade GD, Bair E, Dubner R, Fillingim RB, Ohrbach R, Knott C, Diatchenko L, Liu $\mathrm{Q}$, Maixner W. Pain sensitivity and autonomic risk factors associated with development of TMD: the OPPERA prospective cohort study. J Pain in press. (in this volume).

30. Guasti L, Zanotta D, Diolisi A, Garganico D, Simoni C, Gaudio G, Grandi AM, Venco A. Changes in pain perception during treatment with angiotensin converting enzyme-inhibitors and angiotensin II type 1 receptor blockade. J Hypertens. 2002; 20:485-491. [PubMed: 11875316]

31. Guyant-Maréchal L, Rovelet-Lecrux A, Goumidi L, Cousin E, Hannequin D, Raux G, Penet C, Ricard S, Macé S, Amouyel P, Deleuze J, Frebourg T, Brice A, Lambert J, Campion D. Variations in the APP gene promoter region and risk of Alzheimer disease. Neurology. 2007; 68:684-687. [PubMed: 17325276]

32. Halushka MK, Walker LP, Halushka PV. Genetic variation in cyclooxygenase 1: effects on response to aspirin. Clin Pharmacol Ther. 2003; 73:122-130. [PubMed: 12545150]

33. Harris S, Fox H, Wright A, Hayward C, Starr J, Whalley L, Deary I. A genetic association analysis of cognitive ability and cognitive ageing using 325 markers for 109 genes associated with oxidative stress or cognition. BMC Genetics. 2007; 8:43. [PubMed: 17601350]

34. Heddini U, Bohm-Starke N, Gronblad A, Nyberg F, Nilsson K, Johannesson U. GCH1polymorphism and pain sensitivity among women with provoked vestibulodynia. Mol Pain. 2012; 8:68. [PubMed: 22971341]

35. Herken H, Erdal E, Mutlu N, Barlas O, Cataloluk O, Oz F, Güray E. Possible association of temporomandibular joint pain and dysfunction with a polymorphism in the serotonin transporter gene. Am J Orthod Dentofacial Orthop. 2001; 120:308-313. [PubMed: 11552131]

36. Hocking LJ, Smith BH, Jones GT, Reid DM, Strachan DP, Macfarlane GJ. Genetic variation in the beta2-adrenergic receptor but not catecholamine-O-methyltransferase predisposes to chronic pain: Results from the 1958 British Birth Cohort Study. Pain. 2010; 149:143-151. [PubMed: 20167428]

37. Kang S-C, Lee D-G, Choi J-H, Kim ST, Kim Y-K, Ahn H-J. Association between estrogen receptor polymorphism and pain susceptibility in female temporomandibular joint osteoarthritis patients. Int J Oral Maxillofac Surg. 2007; 36:391-394. [PubMed: 17391927]

38. Karpyak VM, Kim J-H, Biernacka JM, Wieben ED, Mrazek DA, Black JL, Choi D-S. Sequence variations of the human $M P D Z$ gene and association with alcoholism in subjects with European ancestry. Alcohol Clin Exp Res. 2009; 33:712-721. [PubMed: 19175764]

39. Karpyak VM, Geske JR, Colby CL, Mrazek DA, Biernacka JM. Genetic variability in the NMDAdependent AMPA trafficking cascade is associated with alcohol dependence. Addict Biol. 2012; 17:798-806. [PubMed: 21762291]

40. Kim B-S, Kim Y-K, Yun P-Y, Lee E, Bae J. The effects of estrogen receptor a polymorphism on the prevalence of symptomatic temporomandibular disorders. J Oral Maxillofac Surg. 2010; 68:2975-2979. [PubMed: 20656393]

41. Lahiri DK, Ge Y-W, Maloney B, Wavrant-De Vrièze F, Hardy J. Characterization of two APP gene promoter polymorphisms that appear to influence risk of late-onset Alzheimer's disease. Neurobiol Aging. 2005; 26:1329-1341. [PubMed: 16243604]

42. Lee D-G, Kim T-W, Kang S-C, Kim ST. Estrogen receptor gene polymorphism and craniofacial morphology in female TMJ osteoarthritis patients. Int J Oral Maxillofac Surg. 2006; 35:165-169. [PubMed: 16154319]

43. Lee Y, Choi S, Ji J, Song G. Candidate gene studies of fibromyalgia: a systematic review and meta-analysis. Rheumatol Int. 2012; 32:417-426. [PubMed: 21120487] 
44. Lu N, Yang Y, Wang Y, Liu Y, Fu G, Chen D, Dai H, Fan X, Hui R, Zheng Y. ACE2 gene polymorphism essential hypertension: an updated meta-analysis involving 11,051 subjects. Mol Biol Rep. 2012; 39:6581-6589. [PubMed: 22297693]

45. Marques-Lopes J, Pinto M, Pinho D, Morato M, Patinha D, Albino-Teixeira A, Tavares I. Microinjection of angiotensin II in the caudal ventrolateral medulla induces hyperalgesia. Neuroscience. 2009; 158:1301-1310. [PubMed: 19116162]

46. Martínez-Jauand M, Sitges C, Rodríguez V, Picornell A, Ramon M, Buskila D, Montoya P. Pain sensitivity in fibromyalgia is associated with catechol-O-methyltransferase (COMT) gene. Eur J Pain. 2013; 17:16-27. [PubMed: 22528689]

47. Mergener M, Becker RMR, dos Santos AF, dos Santos GA, de Andrade FM. Influence of the interaction between environmental quality and T102C SNP in the HTR2A gene on fibromyalgia susceptibility. Rev Bras Reumatol. 2011; 51:594-602. [PubMed: 22124593]

48. Miao J, Wang F, Fang Y. Association of $231 \mathrm{G}>$ A polymorphism of endothelin type A receptor gene with migraine: A meta-analysis. J Neurol Sci. 2012; 323:232-235. [PubMed: 23058564]

49. Mutlu N, Erdal M, Herken H, Oz G, Bayazit Y. T102C polymorphism of the 5-HT2A receptor gene may be associated with temporomandibular dysfunction. Oral Dis. 2004; 10:349-352. [PubMed: 15533210]

50. Neely GG, Hess A, Costigan M, Keene AC, Goulas S, Langeslag M, Griffin RS, Belfer I, Dai F, Smith SB, Diatchenko L, Gupta V, Xia C-p, Amann S, Kreitz S, Heindl-Erdmann C, Wolz S, Ly CV, Arora S, Sarangi R, Dan D, Novatchkova M, Rosenzweig M, Gibson DG, Truong D, Schramek D, Zoranovic T, Cronin SJF, Angjeli B, Brune K, Dietzl G, Maixner W, Meixner A, Thomas W, Pospisilik JA, Alenius M, Kress M, Subramaniam S, Garrity PA, Bellen HJ, Woolf CJ, Penninger JM. A genome-wide Drosophila screen for heat nociception identifies a2d3 as an evolutionarily conserved pain gene. Cell. 2010; 143:628-638. [PubMed: 21074052]

51. Offenbaecher M, Bondy B, Jonge SD, Glatzeder K, Krüger M, Schoeps P, Ackenheil M. Possible association of fibromyalgia with a polymorphism in the serotonin transporter gene regulatory region. Arthritis Rheum. 1999; 42:2482-2488. [PubMed: 10555044]

52. Ohrbach R, Bair E, Fillingim RB, Gonzales Y, Gordon S, Lim PF, Ribeiro-Dasilva M, Diatchenko L, Dubner R, Greenspan JD, Knott C, Maixner W, Smith SB, Slade GD. Clinical orofacial characteristics associated with risk of first-onset TMD: the OPPERA prospective cohort study. $\mathrm{J}$ Pain in press. (in this volume).

53. Ojima K, Watanabe N, Narita N, Narita M. Temporomandibular disorder is associated with a serotonin transporter gene polymorphism in the Japanese population. Biopsychosoc Med. 2007; 1:3. [PubMed: 17371573]

54. Papassotiropoulos A, Henke K, Stefanova E, Aerni A, Muller A, Demougin P, Vogler C, Sigmund JC, Gschwind L, Huynh K-D, Coluccia D, Mondadori CR, Hanggi J, Buchmann A, Kostic V, Novakovic I, van den Bussche H, Kaduszkiewicz H, Weyerer S, Bickel H, Riedel-Heller S, Pentzek M, Wiese B, Dichgans M, Wagner M, Jessen F, Maier W, de Quervain DJ-F. A genomewide survey of human short-term memory. Mol Psychiatry. 2011; 16:184-192. [PubMed: 20038948]

55. Pelegrini-da-Silva A, Martins AR, Prado WA. A new role for the renin-angiotensin system in the rat periaqueductal gray matter: Angiotensin receptor-mediated modulation of nociception. Neuroscience. 2005; 132:453-463. [PubMed: 15802196]

56. Price AL, Patterson NJ, Plenge RM, Weinblatt ME, Shadick NA, Reich D. Principal components analysis corrects for stratification in genome-wide association studies. Nat Genet. 2006; 38:904909. [PubMed: 16862161]

57. Purcell S, Neale B, Todd-Brown K, Thomas L, Ferreira M, Bender D, Maller J, Sklar P, de Bakker P, Daly M, Sham P. PLINK: a toolset for whole-genome association and population-based linkage analysis. Am J Hum Genet. 2007; 81:559-575. [PubMed: 17701901]

58. Reimann F, Cox JJ, Belfer I, Diatchenko L, Zaykin DV, McHale DP, Drenth JPH, Dai F, Wheeler J, Sanders F, Wood L, Wu T-X, Karppinen J, Nikolajsen L, Mannikko M, Max MB, Kiselycznyk C, Poddar M, te Morsche RHM, Smith SB, Gibson D, Kelempisioti A, Maixner W, Gribble FM, Woods CG. Pain perception is altered by a nucleotide polymorphism in SCN9A. PNAS. 2010; 107:5184-5153. [PubMed: 20147621] 
59. Ribeiro-Dasilva MC, Peres Line SR, Leme Godoy dos Santos MC, Arthuri MT, Hou W, Fillingim RB, Rizzatti Barbosa CM. Estrogen receptor- a polymorphisms and predisposition to TMJ disorder. J Pain. 2009; 10:527-533. [PubMed: 19411060]

60. Rosa MLNM, Guimarães FS, de Oliveira RMW, Padovan CuM, Pearson RCA, Del Bel EA. Restraint stress induces B-amyloid precursor protein mRNA expression in the rat basolateral amygdala. Brain Res Bull. 2005; 65:69-75. [PubMed: 15680546]

61. Saito YA, Mitra N, Mayer EA. Genetic approaches to functional gastrointestinal disorders. Gastroenterology. 2010; 138:1276-1285. [PubMed: 20176021]

62. Sanders AE, Slade GD, Bair E, Fillingim RB, Knott C, Dubner R, Greenspan JD, Maixner W, Ohrbach R. General health status and incidence of first-onset temporomandibular disorder: OPPERA prospective cohort study. J Pain in press. (in this volume).

63. Sayer R, Robertson D, Balfour DJK, Breen KC, Stewart CA. The effect of stress on the expression of the amyloid precursor protein in rat brain. Neurosci Lett. 2008; 431:197-200. [PubMed: 18178006]

64. Schürks M. Genetics of migraine in the age of genome-wide association studies. J Headache Pain. 2012; 13:1-9. [PubMed: 22072275]

65. Smith SB, Maixner DW, Greenspan JD, Dubner R, Fillingim RB, Ohrbach R, Knott C, Slade GD, Bair E, Gibson DG, Zaykin DV, Weir BS, Maixner W, Diatchenko L. Potential genetic risk factors for chronic TMD: Genetic associations from the OPPERA Case Control Study. J Pain. 2011; 12:T92-T101. [PubMed: 22074755]

66. Smith SB, Maixner DW, Fillingim RB, Slade G, Gracely RH, Ambrose K, Zaykin DV, Hyde C, John S, Tan K, Maixner W, Diatchenko L. Large candidate gene association study reveals genetic risk factors and therapeutic targets for fibromyalgia. Arthritis Rheum. 2012; 64:584-593. [PubMed: 21905019]

67. Tammimäki A, Männistö PT. Catechol-O-methyltransferase gene polymorphism chronic human pain: a systematic review and meta-analysis. Pharmacogenet Genomics. 2012; 22:673-691. [PubMed: 22722321]

68. Tegeder I, Lötsch J. Current evidence for a modulation of low back pain by human genetic variants. J Cell Mol Med. 2009; 13:1605-1619. [PubMed: 19228264]

69. Tsolakidou A, Czibere L, Putz B, Trumbach D, Panhuysen M, Deussing J, Wurst W, Sillaber I, Landgraf R, Holsboer F, Rein T. Gene expression profiling in the stress control brain region hypothalamic paraventricular nucleus reveals a novel gene network including Amyloid beta Precursor Protein. BMC Genomics. 2010; 11:546. [PubMed: 20932279]

70. Ulrich CM, Bigler J, Sparks R, Whitton J, Sibert JG, Goode EL, Yasui Y, Potter JD. Polymorphisms in PTGS1 (=COX-1) and risk of colorectal polyps. Cancer Epidemiol Biomarkers Prev. 2004; 13:889-893. [PubMed: 15159324]

71. Vargas-Alarcón G, Fragoso J-M, Cruz-Robles D, Vargas A, Vargas A, Lao-Villadóniga J-I, García-Fructuoso F, Ramos-Kuri M, Hernández F, Springall R, Bojalil R, Vallejo M, MartínezLavín M. Catechol-O-methyltransferase gene haplotypes in Mexican and Spanish patients with fibromyalgia. Arthritis Res Ther. 2007; 9:R110. [PubMed: 17961261]

72. Vickers C, Hales P, Kaushik V, Dick L, Gavin J, Tang J, Godbout K, Parsons T, Baronas E, Hsieh F, Acton S, Patane M, Nichols A, Tummino P. Hydrolysis of biological peptides by human angiotensin-converting enzyme-related carboxypeptidase. J Biol Chem. 2002; 277:14838-14843. [PubMed: 11815627]

73. Visscher C, Ligthart L, van Houtem C, de Jongh A, Boomsma D. Temporomandibular pain disorders are partly heritable: Preliminary results of a Dutch twin study [abstract]. 14th World Congress on Pain. 2012:PF196.

74. Wallace RH, Scheffer IE, Barnett S, Richards M, Dibbens L, Desai RR, Lerman-Sagie T, Lev D, Mazarib A, Brand N, Ben-Zeev B, Goikhman I, Singh R, Kremmidiotis G, Gardner A, Sutherland GR, George AL, Mulley JC, Berkovic SF. Neuronal sodium-channel alpha1-subunit mutations in generalized epilepsy with febrile seizures plus. Am J Hum Genet. 2001; 68:859-865. [PubMed: 11254444] 
75. Xiao Y, He W, Russell IJ. Genetic polymorphisms of the Beta2-adrenergic receptor relate to guanosine protein-coupled stimulator receptor dysfunction in fibromyalgia syndrome. $\mathrm{J}$ Rheumatol. 2011; 38:1095-1103. [PubMed: 21406495]

76. Xu S, Wu W, Sun H, Lu J, Yuan B, Xia Y, De Moor B, Marchal K, Wang X, Xu P, Cheng W. Association of the vascular endothelial growth factor gene polymorphisms $(-460 \mathrm{C} / \mathrm{T},+405 \mathrm{G} / \mathrm{C}$, +936T/C) with endometriosis a meta-analysis. Ann Hum Genet. 2012; 76:464-471. [PubMed: 23061744] 


\section{Perspective}

This article reports the findings of a large candidate gene association study of first-onset TMD and related intermediate phenotypes in the OPPERA Study. Although no genetic markers predicted TMD onset, several genetic risk factors for clinical, psychological, and sensory phenotypes associated with TMD onset were observed. 


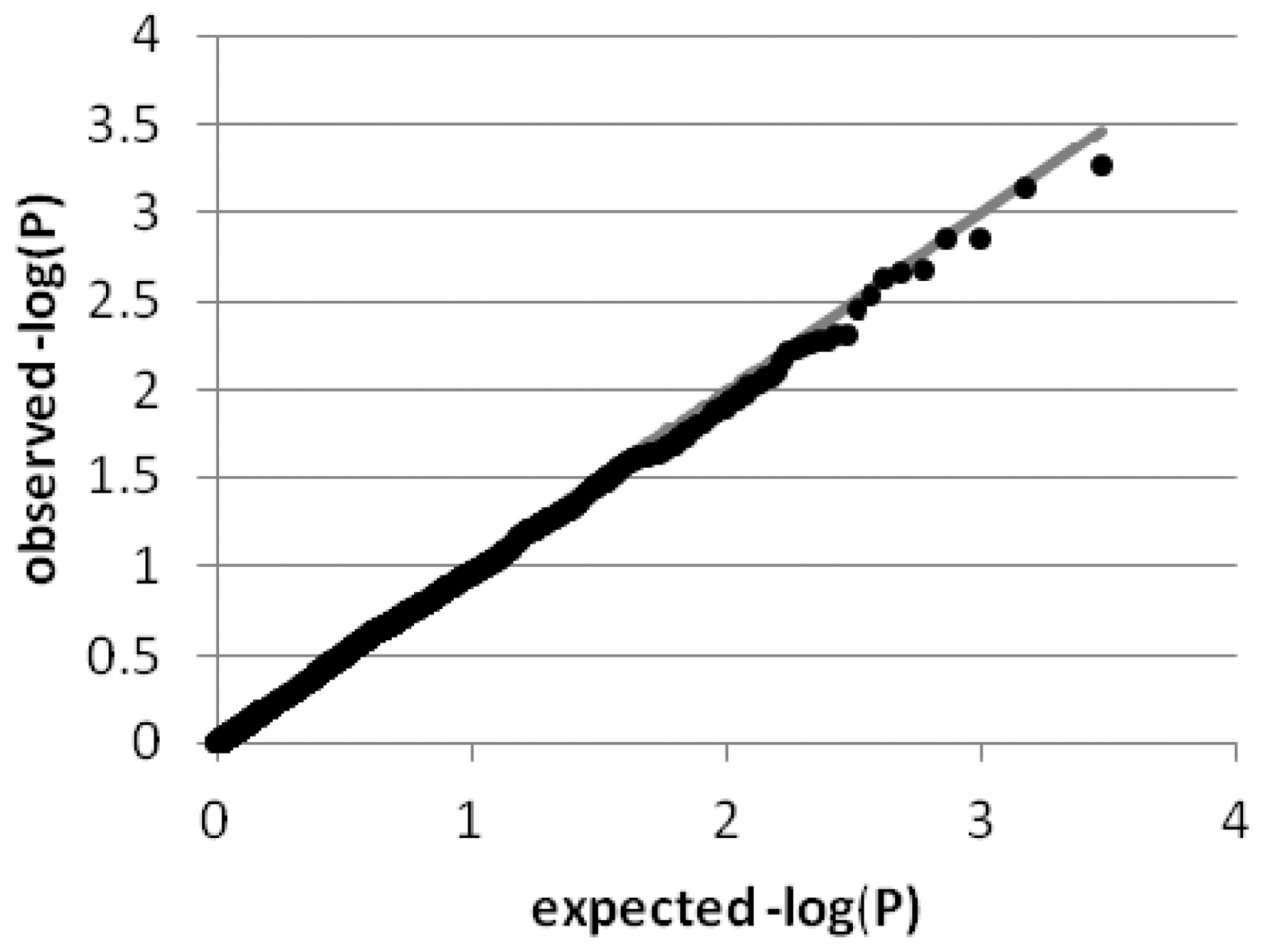

Fig 1.

Q-Q plot of all SNPs in the test of genetic association with TMD incidence Black dots represent the observed $-\log _{10}$ (p-value) for all SNPs passing quality control criteria, compared with the expected values under the null distribution (gray diagonal line). 
a. Non-specific orofacial symptoms

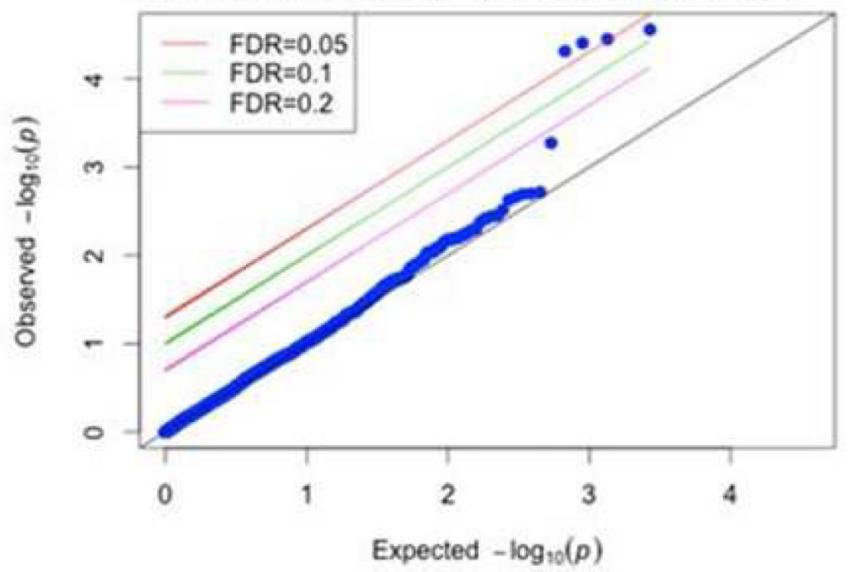

c. Stress and negative affect

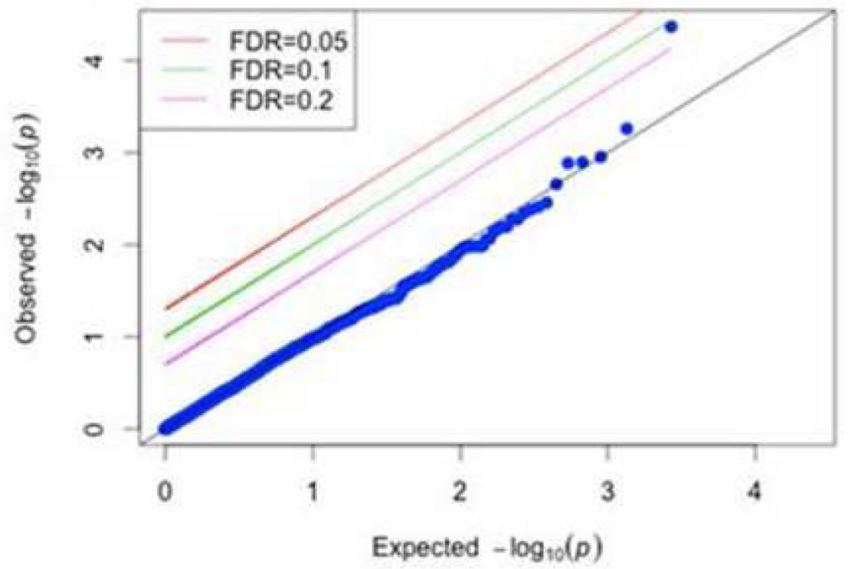

\section{b. Global psychological symptoms}

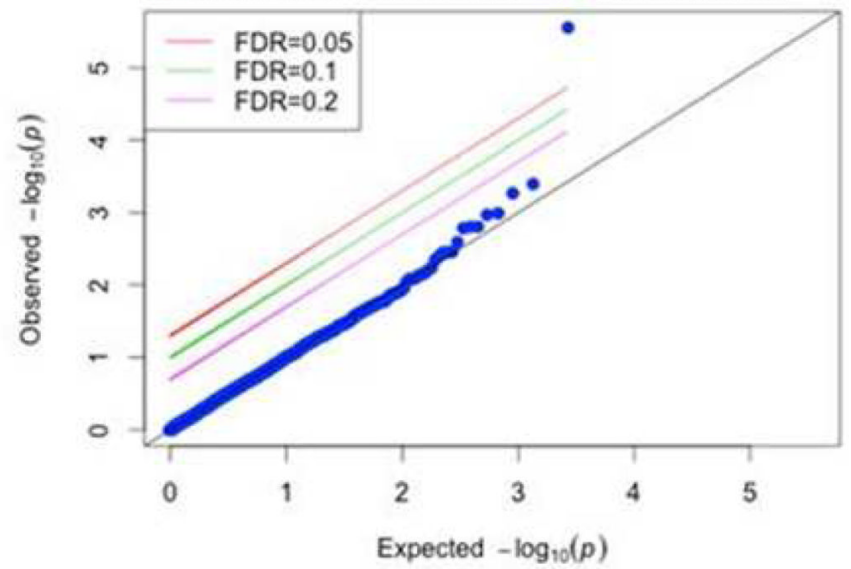

d. Heat pain temporal summation

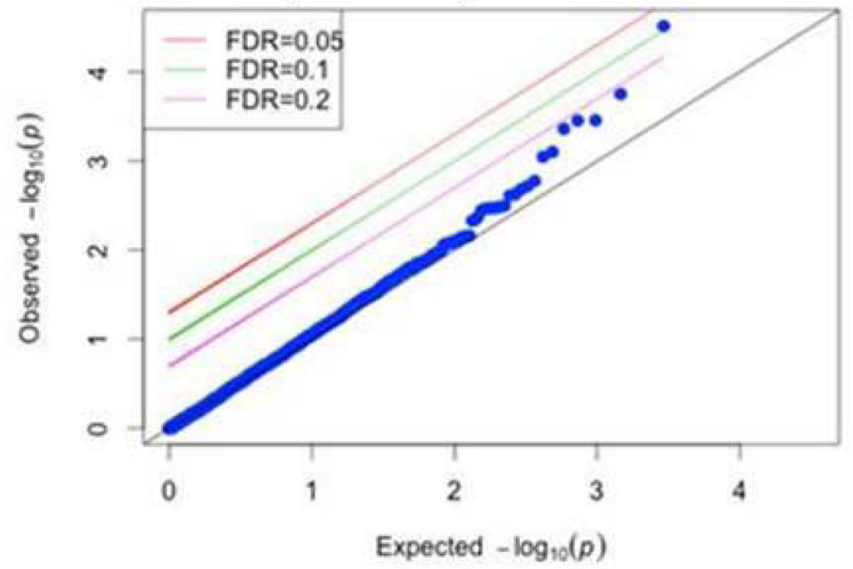

Fig. 2.

Q-Q plots for intermediate phenotypes with SNPs associated at FDR $<0.2$

Q-Q plots of all SNPs in four tests of genetic association with intermediate phenotypes of first-onset TMD. Blue dots represent the observed $-\log _{10}$ (p-value) for all SNPs passing quality control criteria, compared with the expected values under the null distribution (gray diagonal line). Additional colored lines are displayed above the gray line, indicating the thresholds for the false discovery rate as indicated in the key. 


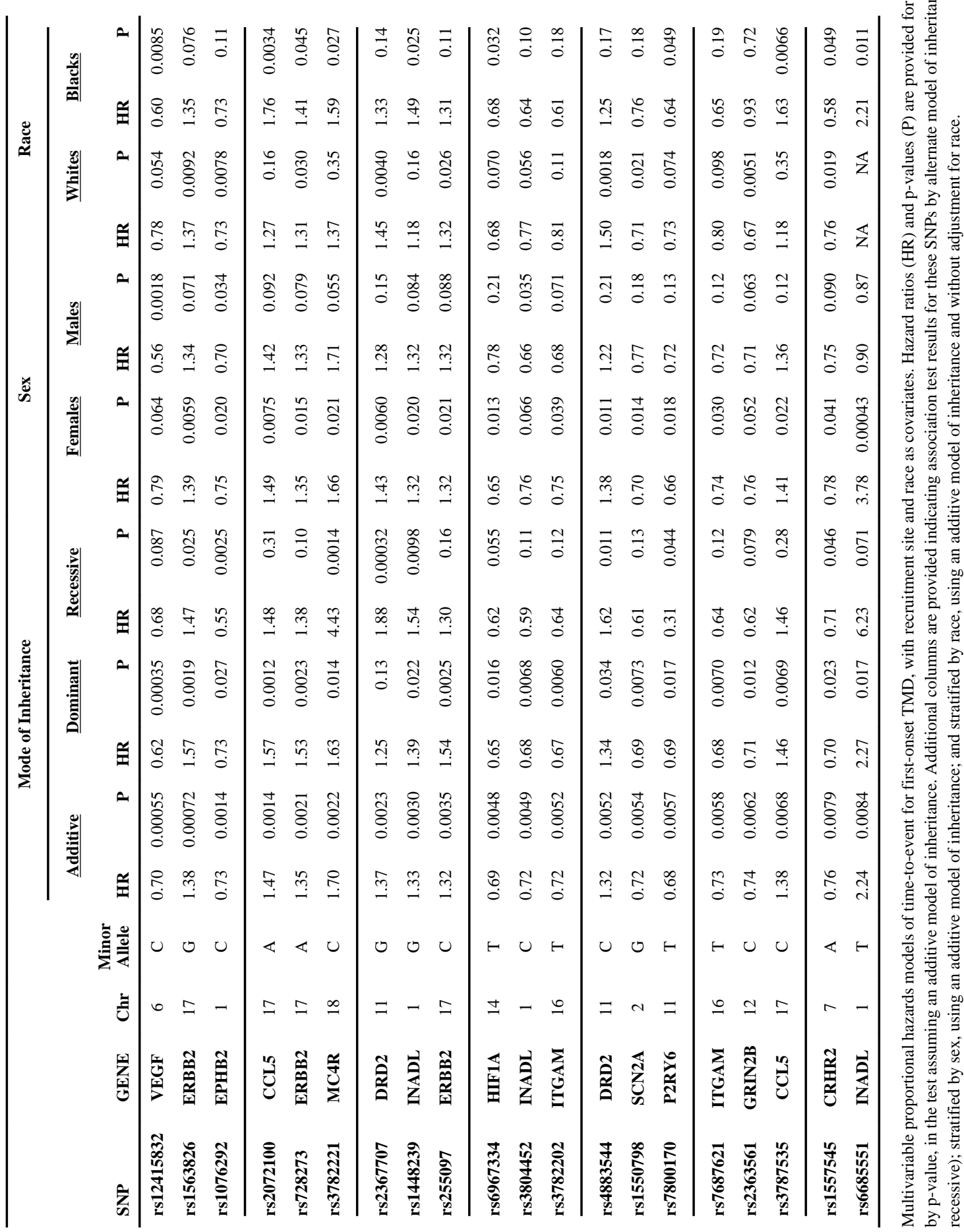




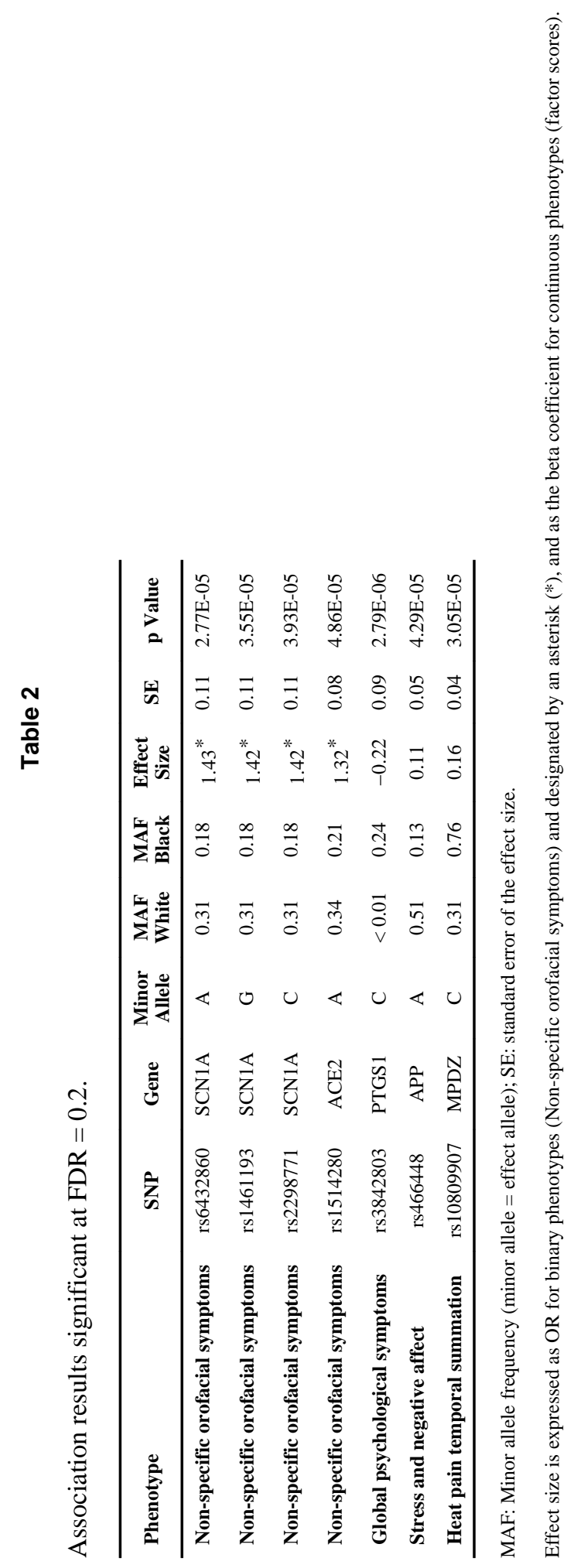

J Pain. Author manuscript; available in PMC 2014 December 01. 